\title{
Retrospective Analysis of the Impact of Adalimumab Initiation on Corticosteroid Utilization and Medical Costs Among Biologic-Naïve Patients with Rheumatoid Arthritis
}

\author{
Christina A. Spivey · Kevin L. Winthrop · Jenny Griffith • \\ Cameron M. Kaplan · Yanru Qiao · Arnold E. Postlethwaite • \\ Junling Wang
}

Received: September 8, 2019 / Published online: November 18, 2019

(c) The Author(s) 2019

\begin{abstract}
Introduction: Treatment guidelines recommend low-dose corticosteroids as short-term therapy among rheumatoid arthritis (RA) patients. However, it may be difficult to wean/ eliminate steroids once initiated. Initiation of more effective therapies such as biologics may help to taper corticosteroid use. The objective was to examine the impact of adalimumab (ADA) initiation on steroid utilization and nondrug medical costs among patients with RA.
\end{abstract}

Enhanced Digital Features To view enhanced digital features for this article go to https://doi.org/10.6084/ m9.figshare.10101389.

C. A. Spivey · Y. Qiao · J. Wang (ه)

University of Tennessee Health Science Center

College of Pharmacy, Memphis, TN, USA

e-mail: jwang26@uthsc.edu

\section{K. L. Winthrop}

Oregon Health \& Science University School of

Public Health, Portland, OR, USA

J. Griffith

AbbVie, Health Economics and Outcomes Research,

North Chicago, IL, USA

C. M. Kaplan

University of Southern California Keck School of

Medicine, Los Angeles, CA, USA

A. E. Postlethwaite

University of Tennessee Health Science Center

College of Medicine, Memphis, TN, USA
Methods: A retrospective analysis was conducted among adult RA patients initiating ADA as the initial biologic in the MarketScan Database (2012-2016). Study outcomes included whether oral/injectable steroids were used, daily dose, dosage categories ( $<5$ and $\geq 5 \mathrm{mg}$ /day), number of steroid injections, and non-drug medical costs. Outcomes were compared 6 months pre- and post-ADA initiation. Mixed effects logistic, classical linear, multinomial logistic models, and linear model with a log link and gamma distribution were used to adjust for patient demographic and health characteristics. Results: The sample included 7404 ADA initiators. Compared to pre-ADA initiation, in the post-initiation period there was a reduction in proportions of patients using oral steroids (from 71.80 to $62.56 \%$ ) and injectable steroids (from 34.91 to $29.88 \%$ ), average daily dose of oral steroids (from 3.30 to $2.62 \mathrm{mg} /$ day), patients with dose $\geq 5 \mathrm{mg} /$ day (from 21.76 to $16.34 \%$ ), number of injections (from 0.64 to 0.53 ), and non-drug medical costs (from $\$ 5356.30$ to $\$ 5146.84)(P<0.01)$. The multivariate analysis produced similar patterns. For example, postADA initiation, patients were less likely to use oral steroids [odds ratio (OR) 0.51 ; $95 \%$ confidence interval (CI) 0.47-0.56]; coefficient estimate for daily dose reduction was - 0.68 (95\% CI -0.81 to -0.56$)$; ratio estimate for medical costs was 0.91 (95\% CI 0.86-0.97).

Conclusions: Among patients with RA, following $\mathrm{ADA}$ initiation, there is a reduction in 
steroid utilization and dosage, and non-drug medical costs. Prospective studies should be conducted to confirm this relationship in the future.

Keywords: Adalimumab; Corticosteroids; Medical costs; Rheumatoid arthritis

\section{Key Summary Points}

Why carry out this study?

Treatment guidelines recommend lowdose corticosteroids as short-term therapy among patients with rheumatoid arthritis (RA).

It may be difficult to wean or eliminate corticosteroids once they are initiated.

The study seeks to examine the impact of adalimumab (ADA) initiation on corticosteroid utilization and non-drug medical costs among patients with RA.

\section{What was learned from the study?}

Results showed that ADA initiation among RA patients was associated with a subsequent reduction in the use of oral and injectable corticosteroids, corticosteroid dosage and number of corticosteroid injections, and non-drug medical costs.

\section{INTRODUCTION}

Rheumatoid arthritis (RA) affects approximately 1.5 million adults in the United States [1]. Due to ongoing immune and inflammatory reactions in the synovium of joints involved, patients can suffer from stiffness, swelling, pain, and loss of joint function. Symptoms may be constant or fluctuate with periods of remission and heightened severity. Bone damage can occur in the early years of the disease, necessitating early medical intervention. Treatment goals for RA are to achieve remission, prevent loss of function and further damage to joints, and improve the patient's quality of life. A few classes of medications can be used in RA treatment, including corticosteroids (steroids) to treat inflammation and disease-modifying antirheumatic drugs (DMARDs) to slow disease progression.

DMARDs play a central role in RA management. The 2015 American College of Rheumatology guideline for the treatment of RA suggests that DMARDs be started at the earliest stage of disease among patients with established RA [2]. Two types of DMARDs are available: nonbiologic and biologic. Nonbiologic DMARDs such as methotrexate and hydroxychloroquine are synthetic medications developed through the conventional drug development process. In contrast, biologic DMARDs are genetically engineered and include both tissue necrosis factor (TNF) inhibitors [e.g., adalimumab (ADA)] and non-TNF inhibitors (e.g., rituximab). Biologic DMARDs may be used as monotherapy or in combination with nonbiologic DMARDS and are recommended for RA patients who are refractory or intolerant to other treatment [3-5]. Furthermore, biologic DMARDs can improve clinical outcomes among RA patients, particularly in combination with a nonbiologic DMARD as noted by Aaltonen et al. [6] and Donahue et al. [7].

Use of biologic DMARDs may also affect the utilization of steroids as co-therapy in RA treatment. Although the 2015 guideline recommends the consideration of low-dose steroids as short-term 'bridge' therapy in RA patients, steroid utilization is associated with serious side effects such as osteoporosis, weight gain, promotion of cataracts in the eyes, worsening of diabetes, and an increased risk of infection $[2,8]$. Yet for many patients, it may be difficult to wean or eliminate steroids once they are initiated [2, 8]. Prior studies suggest deployment of more effective therapies such as biologics may help promote reduction in steroid use [8-12]. For example, Nilsson et al. found that among Danish RA patients taking steroids, initiation of TNF inhibitors resulted in steroid dose reduction in almost half of the patients and discontinuation among one-third of patients [9]. When examining the effects of 
DMARDs on the use of steroids as a co-therapy, however, previous studies have not comprehensively studied the patterns of such effects.

Moreover, changes in the utilization of steroids may have implications for downstream health services and medical costs. For example, the literature has documented the association between the use of steroids and the risk of infection [13, 14]. Furthermore, a study conducted by Yazdany et al. found that RA patients on glucocorticoid monotherapy had increased physician visits and hospitalizations compared to those who had at least one DMARD claim [15]. Likewise, studies such as that by Spivey et al. found that RA patients who used steroids compared to non-users had greater number of physician visits, hospitalizations, and emergency department visits [16]. They also found that steroid users had higher mean healthcare costs than non-users.

Development of a more expansive understanding of these aspects of RA treatment can better inform clinical and policy decision-makers on the appropriate use of biologic DMARDs and steroids as co-therapy. Therefore, the study objective was to examine whether steroid utilization and non-drug medical costs decreased following ADA initiation among patients with RA.

\section{METHODS}

\section{Study Design and Population}

This retrospective cohort study used the Truven MarketScan Commercial Claims and Encounters and Medicare Supplemental and Coordination of Benefits database (1/1/2012-12/31/ 2016) [17].

The MarketScan Database is a de-identified, nationwide medical claims database licensed by Truven Health Analytics Inc. Compliant with the Health Insurance Portability and Accountability Act, the MarketScan Database includes insurance claims of inpatient, outpatient, emergency room, pharmacy, behavioral health care, and enrollment data. Historically, the MarketScan Databases have more than 500 million claim records and claims data from over
100 payers annually, and represent a wide variety of health plans. All claims in the MarketScan Database are linkable using a unique patient identity code. The MarketScan Database has been used widely to study outcomes and patterns of medication utilization.

The study population included adult patients (aged $\geq 18$ years) diagnosed with RA (International Classification of Diseases or ICD9 codes of 714.0 and 714.2 and ICD-10 codes of M05.xx, M06.xx excluding M06.4). The inclusion and exclusion criteria for this study are described in Fig. 1 [13, 18, 19]. To be included, (1) patients must have at least two diagnoses of RA on different dates; (2) ADA initiation had to occur after RA diagnosis; (3) patients needed to have filled a prescription for ADA with no prescription for another biologic DMARD on the same day, and no prescription for ADA or other biologic DMARDs any time before that prescription; (4) ADA initiation date had to occur between 01/01/2013 and 06/30/2016; and (5) patients had to have continuous enrollment in health insurance plans for at least 12 months before the index date and at least 6 months after ADA initiation. Patients were excluded if they met the following criteria at any time in the preindex or post-index periods: had a diagnosis of human immunodeficiency virus (ICD-9 code of 042; ICD-10 code of B20); or had a diagnosis that might impact study outcomes, including some autoimmune diseases such as ulcerative colitis (ICD-9 codes of 556; ICD-10 codes of K51), Crohn's disease (ICD-9 code of 555; ICD10 code of K50), psoriasis (ICD-9 codes of 696.1; ICD-10 codes of L40.0, L40.1, L40.2, L40.8), psoriatic arthritis (ICD-9 codes of 696.0; ICD-10 codes of L40.50, L40.54, L40.59), ankylosing spondylitis (ICD-9 codes of 720.0; ICD-10 codes of M54.9), and hidradenitis suppurativa (ICD-9 code of 705.83; ICD-10 code of L73.2).

The earliest date when a patient initiated ADA is identified as the index date. Study outcomes were compared before and after ADA initiation for the same time duration of 6 months. The study population served as its own control group in the 6-month post-initiation period. 


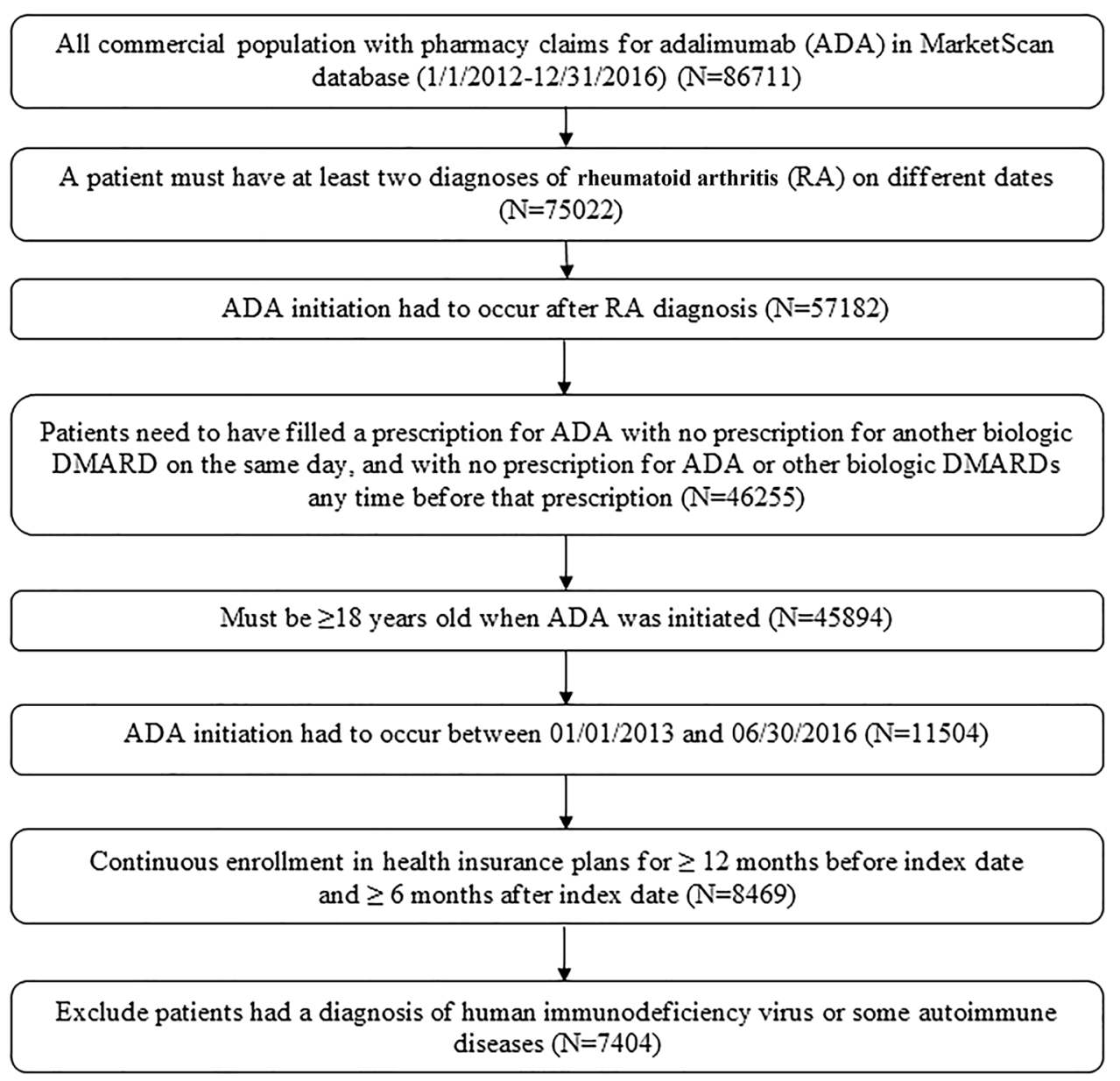

Fig. 1 Flow chart of sample selection

\section{Compliance with Ethics Guidelines}

IRB exemption approval was received (\#1705443-NHSR) from the IRB Office at the corresponding author's institution. Consent to participate is not applicable.

\section{Study Outcomes}

This study examined the impact of initiating ADA on steroid utilization and medical costs among patients with RA. Specifically, study outcomes included the effects of ADA initiation on whether oral or injectable steroids were used, changes in oral steroid daily dose (daily dose was defined as total prednisone equivalence in the observation period divided by the length of the observation period among all patients, number of steroid injections, steroid dosage categories (no use, $<5$ and $\geq 5 \mathrm{mg} /$ day), and non-drug direct medical costs [20-22]. It was also determined whether the average daily dose increased from before to after ADA initiation based on the comparison of the average daily dose between the two periods. Medical costs included total payments for all inpatient and outpatient services, excluding prescription drugs.

Because these study outcomes are all related to the utilization of medications or health services, we used Andersen's Behavioral Model of Health Services Utilization as the theoretical framework for including independent variables in our models [23]. This model classifies determinants of health services utilization into three groups, namely predisposing, enabling, and need factors. Predisposing factors included age, 
gender, types of health plans [comprehensive plans, preferred provider organizations (PPOs), health maintenance organizations (HMOs), and other plans] and ADA initiation year. Enabling factors included metropolitan statistical area, census regions (Northeast, Midwest, South, West, and Unknown), and rheumatologist visit. Need factors included Deyo-adapted Charlson Comorbidity Index (CCI), risk adjustment summary score, and concomitant methotrexate use. The Deyo-adapted CCI is a method of categorizing 17 major comorbidities of patients based on diagnosis code [24, 25]. Risk adjustment summary score is calculated based on diagnostic information from claims. This score was developed based on Diagnostic Cost Group/ Hierarchical Condition Category (DCG/HCC) to risk-adjust payments to Medicare Advantage plans $[26,27]$.

\section{Statistical Analysis}

Steroid utilization and non-drug direct medical costs were compared for 6 months before and after ADA initiation. Descriptive statistics were used to describe patterns of steroid utilization. Mean, standard deviation, and median were reported for continuous variables. Proportions were reported for categorical variables. Differences between pre- and post-index were tested using paired $t$ test for continuous variables. Differences in costs were also tested using the Wilcoxon test because cost variable may not be normally distributed. McNemar's and classical Chi-square tests were used to compare categorical variables pre- and post-index. Mixed effects models were used to adjust for patient characteristics. Specifically, logistic regression was used for dichotomous variables, classical linear regression was used for continuous variables, multinomial logistic regression was used for categorical variables with more than two categories, and generalized linear model with a log link and gamma distribution was used for cost variables. Multinomial instead of ordered logistic regression was used because the assumption of proportionality was violated based on a Brant test. A dummy variable for post-index period was included in regression models to study the effects of ADA use. All variables in Andersen's Model were included as independent variables in the regression models. When analyzing the factors associated with medical costs, average daily dose of steroids was also included in the regression model. Besides these analyses, factors associated with dosage decrease of oral steroids were also examined to explore potential strategies to reduce steroid use. This was achieved by comparing the groups with and without dosage decrease during the post-index period and including as independent variables patient characteristics at baseline. A dose-response relationship was also determined using this same method by including as independent variables measures of steroid utilization patterns in the pre-index period.

Data analysis was conducted using SAS ${ }^{\circledR} 9.4$ (SAS Institute Inc., Cary, NC, USA) and STATA ${ }^{\circledR}$ 13.1 (STATA Corporation, College Stations, TX, USA). The statistical significance level was set a priori at 0.05. Institutional review board approval was obtained from the IRB at the corresponding author's institution.

\section{RESULTS}

The RA patient cohort was comprised of 7404 individuals who met all inclusion criteria. Baseline patient characteristics are summarized in Table 1. Mean age was 52.75 years [standard deviation $(\mathrm{SD})=11.69 \mathrm{]}$, and $22.15 \%$ were male. A small percentage of patients (6.92\%) had comprehensive insurance, over half (61.98\%) had PPO, 9.45\% had HMO, and 21.66\% had other insurance. The proportions of patients who initiated ADA in the years of 2013, 2014, and 2015 were similar at approximately 30\%, while only $8.35 \%$ of patients initiated ADA in 2016. Over $80 \%$ lived in a metropolitan statistical area. Rheumatologist visit occurred in $69.9 \%$ of patients. Mean Deyo-adapted Charlson Comorbidity Index was 1.63 (SD 1.20), and mean risk adjustment summary score was 0.61 (SD 0.56). More than $70 \%$ of patients used methotrexate in the post-index period.

Compared to 6 months pre-ADA initiation, in the post-initiation period, there was a significant reduction in steroid utilization and 
Table 1 Characteristics of adult patients with rheumatoid arthritis $(N=7404)$

\begin{tabular}{|c|c|c|c|}
\hline Characteristics & Groups & Number & Percentage \\
\hline Age & & $\begin{array}{l}\text { Mean, } \\
52.75\end{array}$ & SD, 11.69 \\
\hline \multirow[t]{4}{*}{ Age } & $18-64$ & 6561 & $88.63 \%$ \\
\hline & $65-74$ & 643 & $8.69 \%$ \\
\hline & $75-84$ & 174 & $2.35 \%$ \\
\hline & 85 and Above & 25 & $0.34 \%$ \\
\hline \multirow[t]{2}{*}{ Gender } & Male & 1640 & $22.15 \%$ \\
\hline & Female & 5763 & $77.85 \%$ \\
\hline \multirow{4}{*}{$\begin{array}{l}\text { Types of } \\
\text { insurance } \\
\text { plans }\end{array}$} & Comprehensive & 503 & $6.92 \%$ \\
\hline & $\mathrm{PPO}$ & 4508 & $61.98 \%$ \\
\hline & $\mathrm{HMO}$ & 687 & $9.45 \%$ \\
\hline & Other & 1575 & $21.66 \%$ \\
\hline \multirow{4}{*}{$\begin{array}{l}\text { Adalimumab } \\
\text { initiation year }\end{array}$} & 2013 & 2057 & $27.79 \%$ \\
\hline & 2014 & 2415 & $32.62 \%$ \\
\hline & 2015 & 2313 & $31.24 \%$ \\
\hline & 2016 & 618 & $8.35 \%$ \\
\hline \multirow{2}{*}{$\begin{array}{l}\text { Metropolitan } \\
\text { statistical area }\end{array}$} & No & 1341 & $18.11 \%$ \\
\hline & Yes & 6062 & $81.89 \%$ \\
\hline \multirow{5}{*}{$\begin{array}{l}\text { Geographic } \\
\text { region }\end{array}$} & Northeast & 1083 & $14.63 \%$ \\
\hline & Midwest & 1605 & $21.68 \%$ \\
\hline & South & 3402 & $45.95 \%$ \\
\hline & West & 1181 & $15.95 \%$ \\
\hline & Unknown & 132 & $1.78 \%$ \\
\hline \multirow{2}{*}{$\begin{array}{l}\text { Rheumatologist } \\
\text { visit }\end{array}$} & No & 2229 & $30.11 \%$ \\
\hline & Yes & 5175 & $69.90 \%$ \\
\hline \multicolumn{2}{|c|}{$\begin{array}{l}\text { Deyo-adapted Charlson } \\
\text { Comorbidity Index }\end{array}$} & $\begin{array}{r}\text { Mean, } \\
1.63\end{array}$ & $\mathrm{SD}, 1.20$ \\
\hline \multicolumn{2}{|c|}{ Risk Adjustment Summary Score } & $\begin{array}{r}\text { Mean, } \\
0.61\end{array}$ & $\mathrm{SD}, 0.56$ \\
\hline
\end{tabular}

Table 1 continued

\begin{tabular}{|c|c|c|c|}
\hline Characteristics & Groups & Number & Percentage \\
\hline \multirow{2}{*}{$\begin{array}{l}\text { Methotrexate } \\
\text { use }\end{array}$} & No & 2025 & $27.35 \%$ \\
\hline & Yes & 5379 & $72.65 \%$ \\
\hline
\end{tabular}

$H M O$ health maintenance organization, $P P O$ preferred provider organization, $S D$ standard deviation

medical costs (Table 2). Proportions of patients using oral steroids decreased from 71.80 to $62.56 \%$. Proportions of patients using injectable steroids decreased from 34.91 to $29.88 \%$. Average daily dose of oral steroids decreased from $3.30 \mathrm{mg} /$ day (SD $5.86 \mathrm{mg} /$ day) to $2.62 \mathrm{mg} /$ day (SD $5.33 \mathrm{mg} /$ day). The number of steroid injections decreased from an average of 0.64 per patient (SD 1.15) to 0.53 per patient (SD 1.11). The proportion of patients with steroid dose of zero $\mathrm{mg} /$ day increased from 40.88 to $49.72 \%$, proportion of patients with dose $<5 \mathrm{mg} /$ day decreased from 37.36 to $33.94 \%$, and proportion of patients with dose $\geq 5 \mathrm{mg} /$ day decreased from 21.76 to $16.34 \%$. Mean non-drug medical costs decreased from $\$ 5356.30$ (SD \$11 787.38) in the pre-ADA initiation period to $\$ 5146.84$ (SD $\$ 13,528.09$ ) in the post-ADA initiation period. All outcome comparisons between pre- and post-ADA initiation are significant $(P<0.01)$.

Multivariate analysis found a reduction in steroid utilization in the post-ADA initiation period (Table 3). Odds ratio (OR) for any use of oral steroids was 0.51 [95\% confidence interval (CI) 0.47-0.56]. This number indicates that patients were $49 \%$ less likely to use oral steroids post-initiation versus pre-initiation. Coefficient estimate for daily dose was - 0.68 (95\% CI -0.81 to -0.56$)$ in the post-index period. This suggests that daily dose was $0.68 \mathrm{mg} /$ day lower in the post-initiation period versus pre-initiation period (Table 3 ). The coefficient estimate for the reduction of the number of steroid injections was -0.11 (95\% CI -0.14 to -0.08$)$ in the post-index period.

Post-ADA relative risk ratios (RRR) for dosage categories $<5 \mathrm{mg} /$ day and $\geq 5 \mathrm{mg} /$ day compared 
Table 2 Steroid utilization and non-drug medical costs before and after adalimumab (ADA) initiation among patients with rheumatoid arthritis $(N=7404)$

\begin{tabular}{|c|c|c|c|c|}
\hline Variables & $\begin{array}{l}\text { Before ADA } \\
\text { initiation }\end{array}$ & After ADA initiation & Difference & $P$ value \\
\hline Oral steroid use (percentage) & $71.80 \%$ & $62.56 \%$ & $9.24 \%$ & $<0.01$ \\
\hline Steroid injection (percentage) & $34.91 \%$ & $29.88 \%$ & $5.04 \%$ & $<0.01$ \\
\hline Steroid daily dose, mean (standard deviation) & $\begin{array}{l}3.30 \mathrm{mg} / \text { day } \\
(5.86 \mathrm{mg} / \text { day })\end{array}$ & $\begin{array}{l}2.62 \mathrm{mg} / \text { day } \\
(5.33 \mathrm{mg} / \text { day })\end{array}$ & $0.68 \mathrm{mg} /$ day & $<0.01$ \\
\hline $\begin{array}{l}\text { Number of steroid injections, mean (standard } \\
\text { deviation) }\end{array}$ & $0.64(1.15)$ & $0.53(1.11)$ & 0.11 & $<0.01$ \\
\hline \multicolumn{5}{|l|}{ Average daily dose } \\
\hline$=0$ (no steroid use) & $40.88 \%$ & $49.72 \%$ & $8.84 \%$ & $<0.01$ \\
\hline $0<$ to $<5 \mathrm{mg} /$ day & $37.36 \%$ & $33.94 \%$ & $3.42 \%$ & \\
\hline$\geq 5 \mathrm{mg} /$ day & $21.76 \%$ & $16.34 \%$ & $5.42 \%$ & \\
\hline $\begin{array}{l}\text { Non-drug medical costs, mean (standard } \\
\text { deviation) }\end{array}$ & $\$ 5356.30(\$ 11,787.38)$ & $\$ 5146.84(\$ 13,528.09)$ & $\$ 209.46$ & $<0.01$ \\
\hline
\end{tabular}

to no steroid use were 0.57 (95\% CI $0.52-0.63)$ and 0.47 (95\% CI $0.42-0.52)$, respectively (Table 4). These numbers indicate that patients were $43 \%$ less likely to use $<5 \mathrm{mg} /$ day compared to zero and $53 \%$ less likely to use $\geq 5 \mathrm{mg} /$ day compared to zero, respectively.

Select factors were significantly associated with oral steroid dosage reduction among all patients after ADA initiation (Table 5). When average daily dose in the pre-initiation period was not included, patients who were male (OR 1.15 ; 95\% CI 1.03-1.29) or who used methotrexate (OR 1.30; 95\% CI 1.17-1.45) were more likely to have reduced oral steroid dosage in the post period. Patients who lived in the West (OR 0.75; 95\% CI 0.63-0.89) or Unknown region (OR 0.50; 95\% CI 0.33-0.77) had lowered steroid dosage in the post period. Patients with higher steroid dosage in the pre-index period were more likely to have reduced dosage in the post-index period (OR 1.40; 95\% CI 1.38-1.43), as were those patients who used methotrexate (OR 1.14; 95\% CI 1.01-1.29). Patients who were male (OR 0.85; 95\% CI 0.74-0.98) and had higher risk adjustment score (OR 0.84; 95\% CI
0.74-0.96) were less likely to have dosage reduction in the post-index period.

Non-drug medical costs were significantly reduced after ADA initiation based on adjusted analysis (Table 3). Ratio estimate for non-drug medical costs was 0.91 (95\% CI 0.86-0.97), indicating that non-drug medical costs were reduced by $9 \%$ in the post-ADA initiation period.

\section{DISCUSSION}

The current study examined the effects of ADA initiation on steroid utilization patterns and non-drug medical costs among RA patients. In comparing the two study periods, 6 months before and after ADA initiation, the findings indicated that following initiation of ADA, fewer RA patients used oral steroids or injectable steroids, and fewer patients used lowdose oral steroids $(<5 \mathrm{mg} /$ day $)$ and high-dose oral steroids ( $\geq 5 \mathrm{mg} /$ day). Additionally, RA patients experienced reductions in daily steroid dose, number of steroid injections, and nondrug medical costs after starting ADA. 


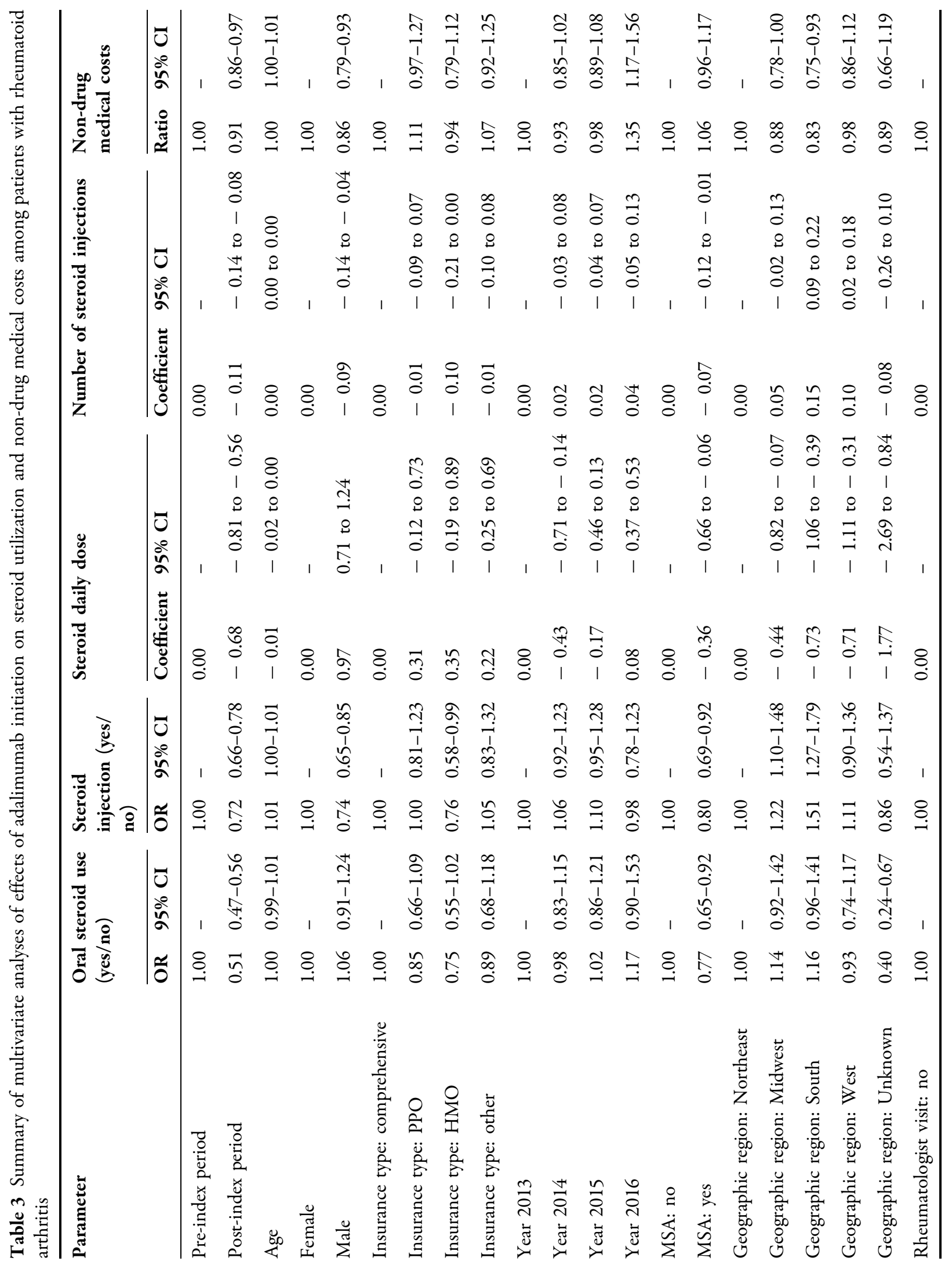




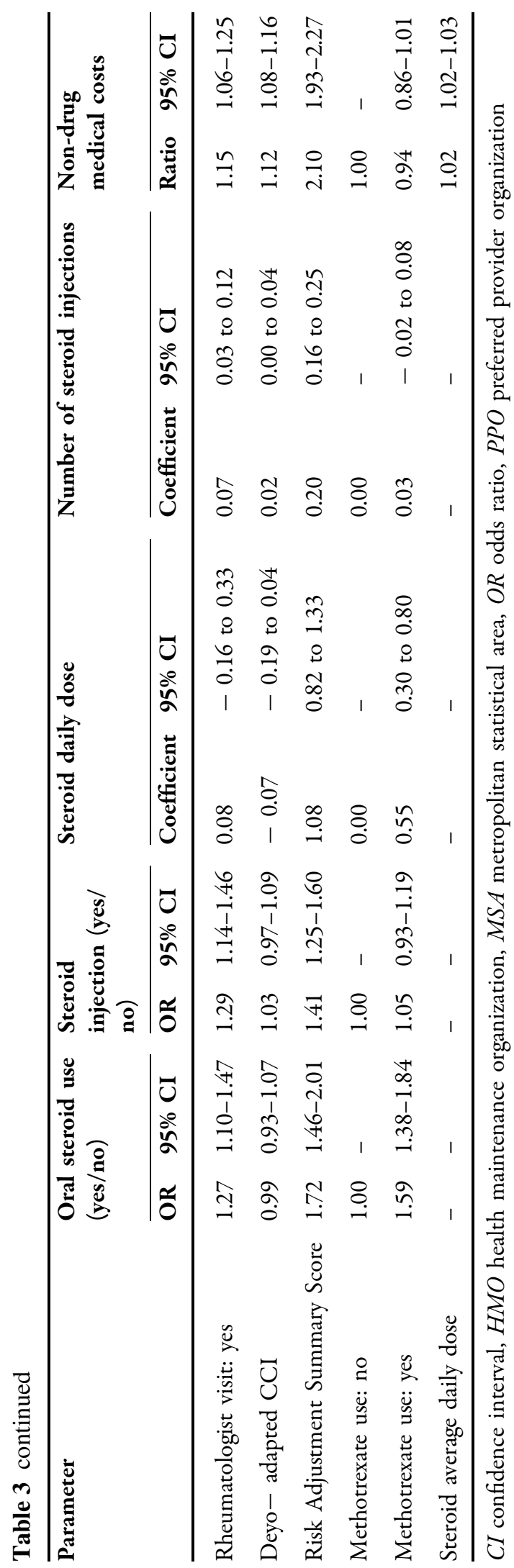

Similar to the findings of the current study, prior studies have consistently noted an association between biologic DMARD initiation/ utilization and reduction in steroid utilization [6-8]. As previously described, Nilsson et al. found that initiation of TNF inhibitors was associated with a reduction or elimination of steroid use among RA patients [9]. Likewise, in a study of more than 6000 RA patients conducted by Accortt et al., initiation of the biologic DMARD etanercept resulted in a decline in the proportion of patients using oral steroids from $70.6 \%$ to $56.7 \%$ [28]. Lathia et al., in a study of Canadian RA patients, found that those who were adherent to biologic DMARD treatment (defined as medication possession ratio $\geq 0.80$ ) had significantly lower steroid utilization compared to nonadherent patients [12]. Additionally, Chu et al. noted that ADA nonadherence among adult RA patients was associated with corticosteroid use [29]. In examining RA treatment trends, Herrinton et al. noted that as use of DMARDs including biologics increased (from 38 to 63\%) between 1998 and 2009, use of steroids decreased (from $23 \%$ to $15 \%$ ) [30]. The cumulative findings of these studies suggest that implementation of medication therapy considered more effective in the treatment of RA, namely biologic DMARDs, is associated with reduced need for less effective co-therapies such as steroids.

In addition to the reduction in the use of oral and injectable steroids, the present study also found that steroid dosage may be impacted by ADA initiation. As aforementioned, we found that average daily dose of oral steroids decreased in the post-initiation period, and number of steroid injections decreased. Additionally, patients were less likely to use low-dose oral steroids ( $<5 \mathrm{mg} /$ day) and less likely to use highdose oral steroids ( $\geq 5 \mathrm{mg} /$ day) in the post-ADA initiation period. Sandhu et al. and Nilsson et al. also found a reduction in number of steroid injections in their RA sample following the initiation of TNF inhibitor therapy $[9,10]$. Similarly, Armstrong et al. and Nilsson et al. found significant reductions in oral steroid dose when comparing before and after initiation of TNF inhibitors; however, Sandhu et al. did not $[9,10,31]$. We speculate these contrasting 
Table 4 Effects of adalimumab initiation on steroid dosage categories among patients with rheumatoid arthritis based on multinomial logistic regression

\begin{tabular}{|c|c|c|c|c|}
\hline \multirow[t]{3}{*}{ Parameter } & \multirow{2}{*}{\multicolumn{2}{|c|}{$\begin{array}{l}\text { Without daily dose } \\
<5 \mathrm{mg} / \text { day vs. no steroid use }\end{array}$}} & \multirow{2}{*}{\multicolumn{2}{|c|}{$\begin{array}{l}\text { With daily dose } \\
\geq 5 \mathrm{mg} / \text { day vs. no steroid use }\end{array}$}} \\
\hline & & & & \\
\hline & $\begin{array}{l}\text { Relative risk } \\
\text { ratio }\end{array}$ & $\begin{array}{l}95 \% \text { confidence } \\
\text { interval }\end{array}$ & $\begin{array}{l}\text { Relative risk } \\
\text { ratio }\end{array}$ & $\begin{array}{l}95 \% \text { confidence } \\
\text { interval }\end{array}$ \\
\hline Pre-index period & 1.00 & - & 1.00 & - \\
\hline Post-index period & 0.57 & $0.52-0.63$ & 0.47 & $0.42-0.52$ \\
\hline Age & 0.99 & $0.99-1.00$ & 0.99 & $0.99-1.00$ \\
\hline Female & 1.00 & - & 1.00 & - \\
\hline Male & 1.07 & $0.90-1.27$ & 1.73 & $1.45-2.06$ \\
\hline Insurance type: comprehensive & 1.00 & - & 1.00 & - \\
\hline Insurance type: $\mathrm{PPO}$ & 0.95 & $0.73-1.24$ & 0.98 & $0.74-1.30$ \\
\hline Insurance type: HMO & 0.73 & $0.52-1.02$ & 0.74 & $0.51-1.06$ \\
\hline Insurance type: other & 0.97 & $0.72-1.30$ & 1.01 & $0.74-1.38$ \\
\hline Year 2013 & 1.00 & - & 1.00 & - \\
\hline Year 2014 & 0.90 & $0.76-1.07$ & 0.81 & $0.68-0.97$ \\
\hline Year 2015 & 0.93 & $0.78-1.10$ & 0.90 & $0.75-1.08$ \\
\hline Year 2016 & 1.01 & $0.59-1.74$ & 0.73 & $0.41-1.30$ \\
\hline Metropolitan statistical area: no & 1.00 & - & 1.00 & - \\
\hline Metropolitan statistical area: yes & 0.90 & $0.75-1.09$ & 0.84 & $0.69-1.03$ \\
\hline Geographic region: Northeast & 1.00 & - & 1.00 & - \\
\hline Geographic region: Midwest & 0.98 & $0.77-1.25$ & 0.89 & $0.69-1.14$ \\
\hline Geographic region: South & 0.97 & $0.79-1.20$ & 0.71 & $0.57-0.89$ \\
\hline Geographic region: West & 0.61 & $0.48-0.79$ & 0.48 & $0.37-0.63$ \\
\hline Geographic region: Unknown & 0.38 & $0.22-0.68$ & 0.29 & $0.15-0.53$ \\
\hline Rheumatologist visit: no & 1.00 & - & 1.00 & - \\
\hline Rheumatologist visit: yes & 1.20 & $1.03-1.40$ & 1.08 & $0.92-1.28$ \\
\hline $\begin{array}{l}\text { Deyo-adapted Charlson Comorbidity } \\
\text { Index }\end{array}$ & 0.98 & $0.91-1.05$ & 1.00 & $0.92-1.08$ \\
\hline Risk Adjustment Summary Score & 1.51 & $1.29-1.77$ & 1.81 & $1.54-2.13$ \\
\hline Methotrexate use: no & 1.00 & - & 1.00 & - \\
\hline Methotrexate use: yes & 1.77 & $1.51-2.07$ & 1.83 & $1.54-2.17$ \\
\hline
\end{tabular}

$H M O$ health maintenance organization, $P P O$ preferred provider organization 
Table 5 Factors associated with oral steroid dosage reduction after ADA initiation among patients with rheumatoid arthritis based on logistic regression

\begin{tabular}{|c|c|c|c|c|}
\hline \multirow[t]{2}{*}{ Parameter } & \multicolumn{2}{|c|}{ Without daily dose } & \multicolumn{2}{|c|}{ With daily dose } \\
\hline & $\begin{array}{l}\text { Odds } \\
\text { ratio }\end{array}$ & $\begin{array}{l}95 \% \text { confidence } \\
\text { interval }\end{array}$ & $\begin{array}{l}\text { Odds } \\
\text { ratio }\end{array}$ & $\begin{array}{l}95 \% \text { confidence } \\
\text { interval }\end{array}$ \\
\hline Average daily dose in pre-period & - & - & 1.40 & $1.38-1.43$ \\
\hline Age & 0.99 & $0.99-0.99$ & 0.99 & $0.99-1.00$ \\
\hline Female & 1.00 & - & 1.00 & - \\
\hline Male & 1.15 & $1.03-1.29$ & 0.85 & $0.74-0.98$ \\
\hline Insurance type: comprehensive & 1.00 & - & 1.00 & - \\
\hline Insurance type: $\mathrm{PPO}$ & 0.87 & $0.73-1.04$ & 0.84 & $0.68-1.03$ \\
\hline Insurance type: $\mathrm{HMO}$ & 0.81 & $0.64-1.01$ & 0.78 & $0.60-1.01$ \\
\hline Insurance type: other & 0.86 & $0.71-1.05$ & 0.80 & $0.64-1.01$ \\
\hline Year 2013 & 1.00 & - & 1.00 & - \\
\hline Year 2014 & 1.00 & $0.88-1.13$ & 1.09 & $0.95-1.26$ \\
\hline Year 2015 & 1.04 & $0.91-1.17$ & 1.10 & $0.95-1.27$ \\
\hline Year 2016 & 1.18 & $0.98-1.43$ & 1.17 & $0.94-1.46$ \\
\hline Metropolitan statistical area: no & 1.00 & - & 1.00 & - \\
\hline Metropolitan statistical area: yes & 0.91 & $0.80-1.03$ & 0.97 & $0.83-1.12$ \\
\hline Geographic region: Northeast & 1.00 & - & 1.00 & - \\
\hline Geographic region: Midwest & 0.97 & $0.83-1.14$ & 1.03 & $0.85-1.24$ \\
\hline Geographic region: South & 0.93 & $0.81-1.07$ & 1.11 & $0.94-1.31$ \\
\hline Geographic region: West & 0.75 & $0.63-0.89$ & 0.94 & $0.77-1.14$ \\
\hline Geographic region: Unknown & 0.50 & $0.33-0.77$ & 0.72 & $0.44-1.17$ \\
\hline Rheumatologist visit: no & 1.00 & - & 1.00 & - \\
\hline Rheumatologist visit: yes & 1.00 & $0.90-1.11$ & 0.99 & $0.88-1.12$ \\
\hline $\begin{array}{l}\text { Deyo-adapted Charlson Comorbidity } \\
\text { Index }\end{array}$ & 0.99 & $0.94-1.04$ & 1.00 & $0.94-1.06$ \\
\hline Risk Adjustment Summary Score & 1.05 & $0.94-1.17$ & 0.84 & $0.74-0.96$ \\
\hline Methotrexate use: no & 1.00 & - & 1.00 & - \\
\hline Methotrexate use: yes & 1.30 & $1.17-1.45$ & 1.14 & $1.01-1.29$ \\
\hline
\end{tabular}

$H M O$ health maintenance organization, $P P O$ preferred provider organization

findings regarding oral steroid dosage may be due to variation in clinical/treatment rationale. Future studies should further examine factors influencing clinical decision-making regarding steroid dosage following implementation of biologic DMARD therapy in RA patients.

Use of steroids as a co-therapy is a concern in RA treatment because they are associated with 
serious side effects that may negatively impact patient outcomes. Spivey et al. found that among RA patients, those who used steroids before the initiation of biologic DMARDs were more likely to experience adverse effects than non-users [16]. Steroid users had higher incidence rates of various adverse effects including but not limited to cardiovascular events, infections, and gastrointestinal problems. Further, these investigators found that steroid users versus non-users experienced significantly greater healthcare utilization and costs. Given the ongoing burden of adverse effects and costs associated with steroid use, the reduction or elimination of steroid utilization achieved following ADA initiation, as demonstrated in the current analysis, is particularly noteworthy.

This study's finding that non-drug medical costs decreased post-ADA initiation compared to pre-initiation is consistent with previous research that demonstrated an association between use of biologic DMARDs and reductions in healthcare utilization. Armstrong et al. noted a significant reduction in hospitalizations following initiation of TNF inhibitors [31]. The findings of Accortt et al. were similar, as were the findings of Lathia et al. who noted that RA patients who were adherent to biologic DMARDs had lower healthcare utilization compared to nonadherent patients [12, 28]. Although these studies did not directly examine healthcare costs, one may presume that significant reductions in healthcare utilization are likely to result in significant reductions in healthcare costs. We speculate that reductions in healthcare utilization and non-drug medical costs following initiation of a biologic DMARD such as ADA may be attributed to improved health, decreased steroid use, and in turn, decreased steroid-related adverse events. Future studies should further evaluate the interplay between use of biologic DMARDs and steroids, and the resultant effects on healthcare utilization and costs.

In addition to the relationships between ADA initiation, steroid utilization, and nondrug medical costs, this study's findings also point to differences in use of both oral and injectable steroids as well as oral steroid dosage and non-drug medical costs based on patient demographics (i.e., gender, region of residence, living in a metropolitan statistical area), risk adjustment score, rheumatologist visit, and methotrexate use. Future studies should address the clinical relevance, if any, of these differences.

This study has limitations. As this was a retrospective observational study, it was impossible to explore the clinical rationale, disease activity and duration, and/or patient background factors that may guide the observed treatment patterns. The study results do not fully reflect the impact of ADA on ability to reduce steroids as no intervention was provided. Additional studies are warranted to determine the causal relationship and full impact of ADA and/or all biologics on ability to withdraw steroids. Additionally, because patients may take medications at doses lower or higher than those prescribed in the database, the method of calculating steroid use may underestimate or overestimate daily dosage or duration of therapy. Another limitation is that this study is based on administrative databases that do not include clinical parameters related to study outcomes such as body mass index, smoking status, and/or lab tests. Finally, a causal relationship between study variables cannot be established based on observational analysis. Therefore, prospective studies are needed to establish causality between ADA initiation and reduction in steroid utilization and non-drug medical costs. Despite these limitations, the methods proposed in this study represent the state of the art for this type of research, and this study produced important findings related to the effects of ADA initiation on steroid utilization among RA patients.

\section{CONCLUSIONS}

In summary, ADA initiation among RA patients was associated with a subsequent reduction in use of oral and injectable steroids, steroid dosage and number of steroid injections, and non-drug medical costs. This study thus provides evidence of the beneficial effect of initiating biologic DMARDs such as ADA on utilization of steroids as an RA co-therapy. 
Clinical and policy decision-makers should consider these findings when determining the appropriate use of biologic DMARDs and steroids as co-therapy. Future studies should continue to evaluate the optimal use of biologic DMARDs such as ADA and steroids in RA treatment.

\section{ACKNOWLEDGEMENTS}

Funding. This study and Rapid Service Fee was funded by AbbVie Inc. AbbVie participated in the study design, research, data collection, analysis, and interpretation of data, writing, reviewing, and approving the publication. All authors had full access to all of the data in this study and take complete responsibility for the integrity of the data and accuracy of the data analysis. All authors contributed to the development of the publication and maintained control over the final content.

Medical Writing, Editorial and other Assistance. The authors would like to acknowledge the assistance from Edward Chiyaka, PhD, with the formatting of the manuscript for submission.

Authorship. All named authors meet the International Committee of Medical Journal Editors (ICMJE) criteria for authorship for this article, take responsibility for the integrity of the work as a whole, and have given their approval for this version to be published.

Disclosures. Christina A. Spivey has received grant/research support from AbbVie. Cameron M. Kaplan has received grant/research support from AbbVie. Yanru Qiao has received grant/ research support from AbbVie. Arnold Postlethwaite has received grant/research support from AbbVie. Junling Wang has received grant/research support from AbbVie. Kevin L. Winthrop has received grant/research support/consultant from AbbVie, Lilly, Pfizer, UCB, Roche, Gilead, and BMS. Jenny Griffith is a shareholder/employee of AbbVie.
Compliance with Ethics Guidelines. IRB exemption approval was received (\#17-05443NHSR) from the IRB Office at the corresponding author's institution. Consent to participate is not applicable.

Data Availability. The datasets analyzed during the current study are not publicly available due to proprietary reasons but are available from Truven Health Analytics.

Open Access. This article is distributed under the terms of the Creative Commons Attribution-NonCommercial 4.0 International License (http://creativecommons.org/licenses/ by-nc/4.0/), which permits any noncommercial use, distribution, and reproduction in any medium, provided you give appropriate credit to the original author(s) and the source, provide a link to the Creative Commons license, and indicate if changes were made.

\section{REFERENCES}

1. National Institute of Arthritis and Musculoskeletal and Skin Diseases. Rheumatoid arthritis. April 30, 2017. https://www.niams.nih.gov/health-topics/ rheumatoid-arthritis. Accessed Sept 2019.

2. Singh JA, Saag KG, Bridges SL Jr, et al. 2015 American College of Rheumatology guidelines for the treatment of rheumatoid arthritis. Arthritis Care Res. 2016;68:1-25.

3. Tanaka Y. Next stage of RA treatment: is TNF inhibitor-free remission a possible treatment goal? Ann Rheum Dis. 2013;72:ii124-7.

4. Burmester GR, Kivitz AJ, Kupper H, et al. Efficacy and safety of ascending methotrexate dose in combination with adalimumab: the randomised CONCERTO trial. Ann Rheum Dis. 2015;74: 1037-44.

5. Oh K, Ito S, Unno M, et al. The rate of decrease in the disease activity of rheumatoid arthritis during treatment with adalimumab depends on the dose of methotrexate. Intern Med. 2015;54:1035-41.

6. Aaltonen KJ, Virkki LM, Malmivaara A, Konttinen YT, Nordström DC, Blom M. Systematic review and meta-analysis of the efficiency and safety of existing TNF blocking agents in treatment of rheumatoid arthritis. PLoS One. 2012;7:e30275. 
7. Donahue KE, Jonas DE, Hansen RA, et al. Drug therapy for rheumatoid arthritis in adults: an update. Comparative effectiveness review number 55. Rockville: Agency for Healthcare Research and Quality; 2012. https://www.ncbi.nlm.nih.gov/ books/NBK97388/pdf/Bookshelf_NBK97388.pdf.

Accessed Sept 2019.

8. Kawai VK, Grijalva CG, Arbogast PG, et al. Changes in cotherapies after initiation of disease-modifying antirheumatic drug therapy in patients with rheumatic arthritis. Arthritis Care Res. 2011;63:1415-24.

9. Nilsson AC, Christensen AF, Junker P, Lindegaard HM. Tumour necrosis factor- $\alpha$ inhibitors are glucocorticoid-sparing in rheumatoid arthritis. Dan Med Bull. 2011;58:A4257.

10. Sandhu RS, Treharne GJ, Douglas KM, et al. The impact of anti-tumour necrosis factor therapy for rheumatoid arthritis on the use of other drugs and hospital resources in a pragmatic setting. Musculoskelet Care. 2006;4:204-22.

11. Caplan L, Wolfe F, Russell AS, Michaud K. Corticosteroid use in rheumatoid arthritis: prevalence, predictors, correlates, and outcomes. J Rheumatol. 2007;34:696-705.

12. Lathia U, Ewara EM, Nantel F. Impact of adherence to biological agents on health care resource utilization for patients over the age of 65 years with rheumatoid arthritis. Patient Prefer Adher. 2017;11: 1133-42.

13. Grijalva CG, Kaltenbach L, Arbogast PG, Mitchel EF Jr, Griffin MR. Initiation of rheumatoid arthritis treatments and the risk of serious infections. Rheumatology (Oxford). 2010;49:82-90.

14. Chaudhary NS, Donnelly JP, Moore JX, Baddley JW, Safford MM, Wang HE. Association of baseline steroid use with long-term rates of infection and sepsis in the REGARDS cohort. Crit Care. 2017;21: 185. https://doi.org/10.1186/s13054-017-1767-1.

15. Yazdany J, Tonner C, Schmajuk G, Lin GA, Trivedi AN. Receipt of glucocorticoid monotherapy among Medicare beneficiaries with rheumatoid arthritis. Arthritis Care Res. 2014;66:1447-55.

16. Spivey CA, Griffith J, Kaplan C, Postlethwaite A, Ganguli A, Wang J. A retrospective analysis of corticosteroid utilization before initiation of biologic DMARDs among patients with rheumatoid arthritis in the United States. Rheumatol Ther. 2018;5: 255-70. https://doi.org/10.1007/s40744-017.

17. Truven Health MarketScan Research Databases. Truven health analytics. 2018. http://truvenhealth. com/assets/HP_11517_0912_
MarketScanResearchDatabasesForHP_SS_WEB.pdf. Accessed Sept 2019.

18. Schmajuk G, Trivedi AN, Solomon DH, et al. Receipt of disease-modifying antirheumatic drugs among patients with rheumatoid arthritis in Medicare managed care plans. JAMA. 2011;305: 480-6.

19. Schmajuk G, Schneeweiss S, Katz JN, et al. Treatment of older adult patients diagnosed with rheumatoid arthritis: improved but not optimal. Arthritis Rheum. 2007;57:928-34.

20. van Staa TP, Leufkens HG, Abenhaim L, Begaud B, Zhang B, Cooper C. Use of oral steroids in the United Kingdom. Mon J Assoc Physicians. 2000;93: 105-11.

21. van Staa TP, Leufkens HG, Abenhaim L, Zhang B, Cooper C. Oral steroids and fracture risk: relationship to daily and cumulative doses. Rheumatology. 2000;39:1383-9.

22. Meikle AW, Tyler FH. Potency and duration of action of glucocorticoids. Am J Med. 1977;63: 200-7.

23. Gelberg L, Andersen RM, Leake BD. The behavioral model for vulnerable populations: application to medical care use and outcomes for homeless people. Health Serv Res. 2000;34:1273-302.

24. Deyo RA, Cherkin DC, Ciol MA. Adapting a clinical comorbidity index for use with ICD-9-CM administrative databases. J Clin Epidemiol. 1992;45: 613-9.

25. Quan H, Sundararajan V, Halfon P, et al. Coding algorithms for defining comorbidities in ICD-9-CM and ICD-10 administrative data. Med Care. 2005;43:1130-9.

26. Stuart B, Doshi JA, Briesacher B, Wrobel MV, Baysac F. Impact of prescription coverage on hospital and physician costs: a case study of Medicare beneficiaries with chronic obstructive pulmonary disease. Clin Ther. 2004;26:1688-99.

27. Centers for Medicare \& Medicaid Services. Part D Payment and Risk Adjustment. 2006. https://www. cms.gov/Medicare/Prescription-Drug-Coverage/ DrugCoverageClaimsData/RxClaims_ PaymentRiskAdjustment.html. Accessed Sept 2019.

28. Accortt NA, Schenfeld J, Chang E, Papoyan E, Broder MS. Changes in healthcare utilization after etanercept initiation in patients with rheumatoid arthritis: a retrospective claims analysis. Adv Ther. 2017;34:2093-103. 
29. Chu LH, Kawatkar AA, Gabriel SE. Medication adherence and attrition to biologic treatment in rheumatoid arthritis patients. Clin Ther. 2015;37: 660-6.

30. Herrinton LJ, Harrold L, Salman C, et al. Population variations in rheumatoid arthritis treatment and outcomes, Northern California, 1998-2009. Perm J. 2016;20:4-12.

31. Armstrong DJ, McCausland EM, Wright GD. The impact of anti-TNF- alpha therapy on the nature of service provision. Rheumatology. 2006;45:112. 